\title{
Study of Atkinson cycle in two-stroke diesel engine with opposed pistons
}

The paper presents possibilities of change working parameters of two-stroke diesel engine with opposed pistons. Obtaining of higher engine efficiency is realized by applying of Atkinson cycle. Modification of scavenging process by changing pistons' position connecting with two crankshafts enables asymmetrical scavenge timing. Decreasing of shorter time of closing exhaust ports before compression process and longer expansion process give higher engine work and with high charging ratio increases engine power. These types of engines are recently recommended for power plant stations. The paper includes full analysis of engine work with scavenge and combustion processes for different timing phases based on geometry of the CI Leyland L60 engine by using of CFD modelling and own OD model. Simulation tests indicate a high scavenge efficiency, good penetration of injected fuel and fast combustion process. The work contains figures of pressure, temperature traces and emission of main chemical species in exhaust gases with comparison of engine works for different timing phases. Atkinson cycle in two-cycle work of engine and full combustion process enables to achieve high total efficiency. The study is an input for realization of such processes in a future of power plant engines with different fuelling systems.

Key words: transport, two-stroke opposite piston engine, Atkinson cycle, scavenging, timing phases

\section{Introduction}

Two-stroke opposed piston engines (called from here as "2sOPE") have been and are among the more important ones used in power engineering, on ships, military and industrial equipment because their simplicity, high power density, compactness and lower weights. They do not need of a cylinder head. For this reason, the thermal losses are lower than in hour-stroke engines. Two piston crowns form a combustion chamber often as a shape of distorted spherical chamber. The diesel engines of this type are equipped with fuel injectors placed radially on the circumference of the cylinder. One of the problems is transfer of the drive from two independent crankshafts, usually by a set of gears. One of the pistons controls opening of inlet ports called also as transfer ports and the other controls the exhaust ports. The air is delivered by one pipe or many pipes to transfer chamber surrounding the transfer ports usually on the whole cylinder circumference forcing the air to rotate in the cylinder. On the other hands the exhaust gases leave the cylinder by opening of the exhaust port controlled by the edge of the second piston.

The classical two-stroke engine has symmetrical timing of phases for gas exchange and for that reason the engine loses a lot of mass of charge and sometimes also the fuel. In order to stop such phenomenon, the 2sOPE enables applying of asymmetric opening of the exhaust ports relative to the transfer ports thanks to a different location of the two crankshafts.

Currently, there is a large interest in the use of big CI engines for production of electricity including the $2 \mathrm{sOPE}$ due to a significant power factor. An increase of the engine power and decrease of fuel consumption and exhaust gas emission in such engines is possible by applying of the Atkinson solution. The purpose of the work was to obtain information on the impact of changing the ports opening phases of the engine on the operating parameters.

\section{Atkinson solution in IC engines}

The increase of engine power can be realized by getting more internal work. In 1882 English engineer James Atkinson patented his combustion engine, which enabled a small compression work and larger expansion work in comparison to Otto engine. One of his patents is shown in Fig. 1. However, this solution is realized recently particularly in many hybrid engines [9]. For almost constant rotational speed of the crankshaft the engines give larger torque. Sendyka and Sochan [11] presented the application of Atkinson cycle in a motorcycle 4-stroke SI engine.

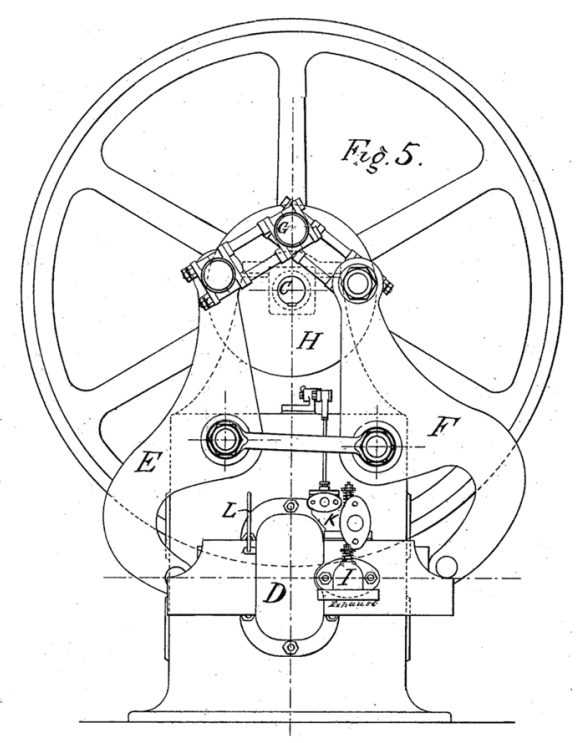

Fig. 1. Patent drawing of the Atkinson "Differential Engine", 1882 [7]

In a classical two-stroke engine realization of Atkinson cycle is almost not possible, but in the past, there were produced many industrial, military and marine two-stroke engines with opposed pistons, which the Atkinson cycle has been applied. One of the most known engines is the 6-cylinder engine Leyland L60 applied by the British army in tanks for very long time. The diagram of the one-cylinder section of this engine is shown in Fig. 2. The other solution of 2sOPE is Rolls Royce K60 with phase shift of two crankshafts enabling asymmetric scavenge process. In twostroke engines with charging of the fresh air during scavenge process a large amount of the air is escaping to the exhaust ports because a large pressure difference. In four- 
stroke engine such situation does not take place. Now the 2sOPE have their renaissance and are generally applied in local energetic plants and other commercial applications [10]. Their advantages were recently described by industry and scientific engineers e.g. from Achates Power [5, 6], how to increase their power and efficiency.

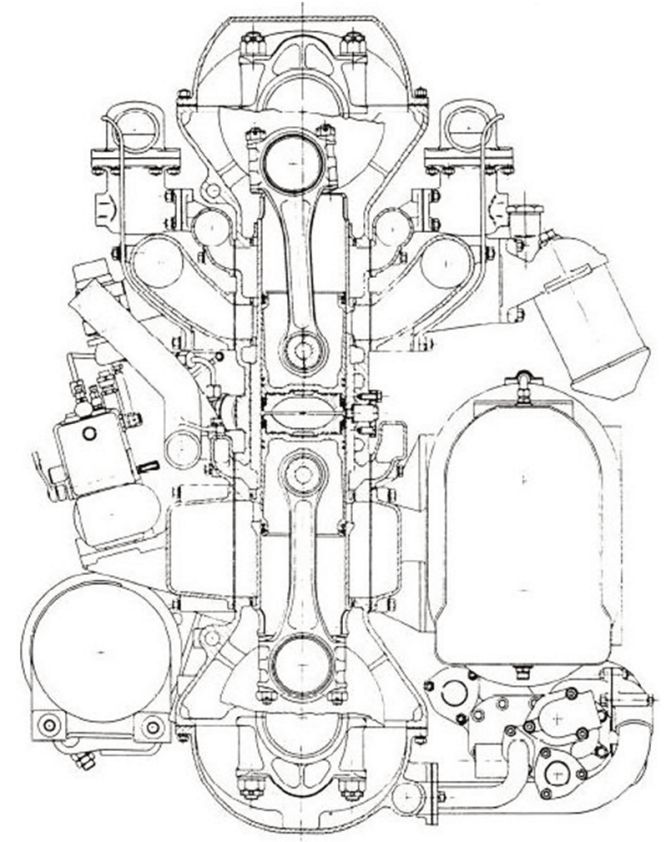

Fig. 2. Leyland L60 two-stroke opposed piston engine

\section{Modification of timing system in two-stroke opposite piston engine}

Two pistons connected with two separate crankshafts allow to change the exhaust port opening phase relative to the transfer port. The crank of the piston, which reveals and close the exhaust port (called as "exhaust piston") can be moved a certain angle relative to the crank of the other piston (called as "transfer piston"). In the classical two stroke engine, only symmetric phases are realized as shown in Fig. 3. The angle $\alpha_{w}$ denotes opening of the exhaust port from TDC and angles $\alpha_{1}=\alpha_{2}$ are the delay angles of the transfer port opening.

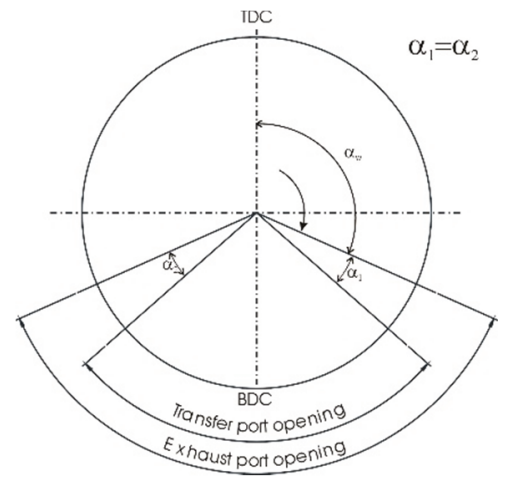

Fig. 3. Symmetric phase timing in two-stroke engine

The Atkinson cycle can be realized by changing of $\alpha_{1}$ of a certain angle $\Delta \alpha$, then also the angle $\alpha_{2}$ changes by a value $\Delta \alpha$. In this paper it was assumed that the reference crank is the crank of the "transfer port". Later opening of the exhaust port is shown in Fig. 4 and for this case after closing of the transfer port the exhaust port is opened for a longer time. On the other hands the expansion process lasts longer than for symmetric timing. In four stroke engines working at Atkinson cycle this case is mostly applied due to greater efficiency. The question is whether this is also valid for two-stroke opposite piston engine.

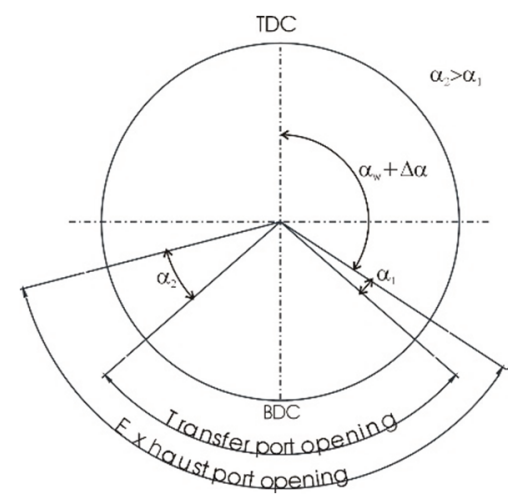

Fig. 4. Asymmetric phase timing in $2 \mathrm{sOPE}$ (delay of exhaust ports opening)

Earlier opening of the exhaust port relative to the symmetric timing causes also earlier closing of this port. The timing of such case is shown in Fig. 5, where the angle $\alpha_{1}$ is bigger than $\alpha_{2}$. Earlier opening of the exhaust port shortens the expansion process and prolongs the compression process. In four stroke engines working with Atkinson cycle causes lower engine efficiency.

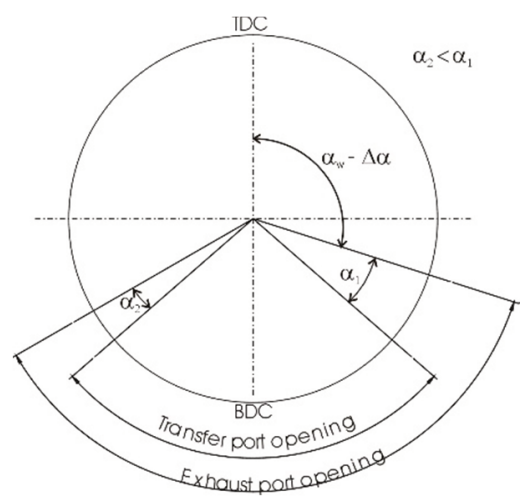

Fig. 5. Asymmetric phase timing in 2sOPE (earlier opening of exhaust ports)

Theoretical cycle of diesel engine assumes that whole dose of fuel is burned at constant pressure. But the work of real diesel engines can be presented according to the Sabathe's cycle, where a part of fuel is burned also at isochoric process. The modified Atkinson cycle for two-stroke opposed diesel engine is presented in Fig. 6 with asymmetric opening (p. 1) and closing (p. 5) of exhaust ports.

Compression of the charge takes place after CE in point 1 and expansion of exhaust gases finishes at point 5, but also after opening of the exhaust ports the gas pressure is still high and does the work. The outflow process (5-6) is almost linear and it reflects the real process. 


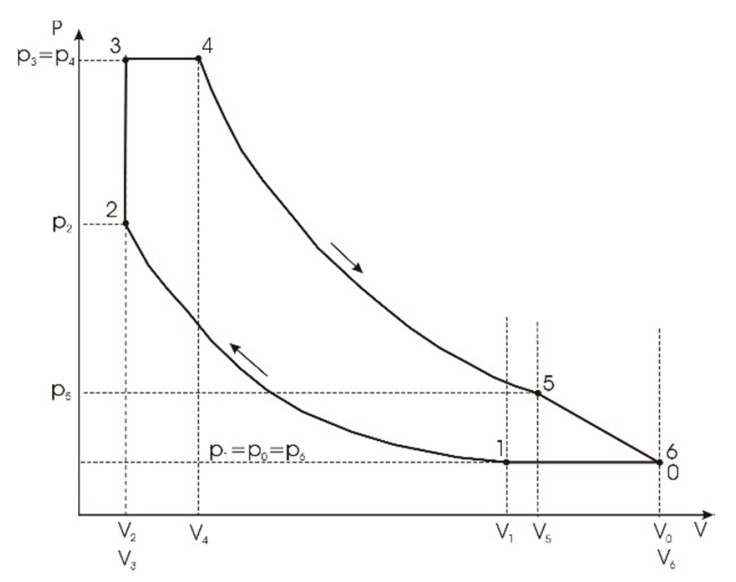

Fig. 6. Modified theoretical Atkinson work cycle in 2 sOPE

\section{Mathematical model of Atkinson work cycle in diesel two-stroke opposed piston engine}

Wide mathematical description of Atkinson cycle for 4-stroke engines gave Ebrahimi [2] in aspect of $\lambda$, fuel mass flow rate and residual gases. In the model of $2 \mathrm{sOPE}$ it was assumed that the stroke towards TDC takes place from $-180^{\circ}$ to $0^{\circ}$ according to crank rotation of the piston $\mathrm{A}$ and the stroke to BDC takes place from $0^{\circ}$ to $180^{\circ}$. The simple theoretical model of an engine working cycle does not take into account the processes of fuel injection and evaporation and also combustion process. For that reason only the energy contained in fuel is considered in the model. Realization of the Atkinson cycle takes place when the angle position of the crank, which controls the exhaust piston B is different in relation to the position to the crank of the piston A, which controls the transfer ports of a certain angle $\Delta \alpha$.

$$
\alpha_{B}=\alpha_{A}+\Delta \alpha
$$

So, movements of both pistons $h_{A}$ and $h_{B}$ from TDC is calculated from the below equations:

$$
\begin{aligned}
& \mathrm{h}_{\mathrm{A}}=\mathrm{r}_{\mathrm{A}}\left(1+\frac{\delta_{\mathrm{A}}}{4}-\cos \alpha_{\mathrm{A}}-\frac{\delta_{\mathrm{A}}}{4} \cos \left(2 \alpha_{\mathrm{A}}\right)\right) \\
& \mathrm{h}_{\mathrm{B}}=\mathrm{r}_{\mathrm{B}}\left(1+\frac{\delta_{\mathrm{B}}}{4}-\cos \alpha_{\mathrm{B}}-\frac{\delta_{\mathrm{B}}}{4} \cos \left(2 \alpha_{\mathrm{B}}\right)\right)
\end{aligned}
$$

where $\mathrm{r}_{\mathrm{A}}, \mathrm{r}_{\mathrm{B}}$ are the cranks and $\delta_{\mathrm{A}}=\mathrm{r}_{\mathrm{A}} / \mathrm{l}_{\mathrm{A}}$ and $\delta_{\mathrm{B}}=\mathrm{r}_{\mathrm{B}} / \mathrm{l}_{\mathrm{B}}$, $l_{A}$ and $l_{B}$ are connecting rod lengths. Cylinder volume for each crank position $\alpha$ of the piston A is calculated as follows:

$$
\mathrm{V}=\mathrm{V}_{\mathrm{k}}+\mathrm{F}\left(\mathrm{h}_{\mathrm{A}}+\mathrm{h}_{\mathrm{B}}\right)
$$

where $\mathrm{F}$ is the piston area. Minimal volume of the combustion chamber $V_{k}$ is defined on the known value of compression ratio $\varepsilon$ and strokes of both pistons $\mathrm{S}_{\mathrm{A}}$ and $\mathrm{S}_{\mathrm{B}}$ :

$$
\mathrm{V}_{\mathrm{k}}=\frac{\mathrm{F}\left(\mathrm{S}_{\mathrm{A}}+\mathrm{S}_{\mathrm{B}}\right)}{\varepsilon-1}
$$

Maximal cylinder volume at point 0 amounts:

$$
\mathrm{V}_{0}=\mathrm{V}_{6}=\mathrm{V}_{\mathrm{k}}+\mathrm{FS}_{\mathrm{A}}+\mathrm{Fh}_{\mathrm{A}}(\pi+\Delta \alpha)
$$

Volumes at points 1 and 5 are calculated on the base of knowing values of exhaust port opening angle $\alpha_{w}$ at sym- metrical phases. Crank angles of the piston A when exhaust ports are closed and opened are defined by the below formulas:

$$
\begin{aligned}
& \alpha_{\mathrm{B} 1}=-\alpha_{\mathrm{w}}+\Delta \alpha \\
& \alpha_{\mathrm{B} 5}=\alpha_{\mathrm{w}}+\Delta \alpha
\end{aligned}
$$

Knowing these values one can calculates the cylinder volumes at points 1 and 5 :

$$
\begin{gathered}
\mathrm{V}_{1}=\operatorname{Fr}_{\mathrm{B}}\left(1+\frac{\delta_{\mathrm{B}}}{4}-\cos \alpha_{\mathrm{B} 1}-\frac{\delta_{\mathrm{B}}}{4} \cos \left(2 \alpha_{\mathrm{B} 1}\right)\right) \\
\mathrm{V}_{5}=\operatorname{Fr}_{\mathrm{B}}\left(1+\frac{\delta_{\mathrm{B}}}{4}-\cos \alpha_{\mathrm{B} 5}-\frac{\delta_{\mathrm{B}}}{4} \cos \left(2 \alpha_{\mathrm{B} 5}\right)\right)
\end{gathered}
$$

At Atkinson cycle for diesel engine a part of the injected fuel is burned at constant volume $\mathrm{V}_{2}$ equal to the minimal cylinder volume $\mathrm{V}_{\mathrm{k}}$ :

$$
\mathrm{V}_{2}=\mathrm{V}_{3}=\mathrm{V}_{\mathrm{k}}
$$

Compression process takes place from point 1 to point 2 and pressure at point 2 at assumption of adiabatic process with heat ratio coefficient $m$ has value:

$$
\mathrm{p}_{2}=\mathrm{p}_{1}\left(\frac{\mathrm{V}_{1}}{\mathrm{~V}_{2}}\right)^{\mathrm{m}}
$$

and temperature reaches value:

$$
\mathrm{T}_{2}=\mathrm{T}_{1}\left(\frac{\mathrm{V}_{1}}{\mathrm{~V}_{2}}\right)^{\mathrm{m}-1}
$$

Mass of the injected fuel $\mathrm{m}_{\mathrm{f}}$ is calculated based on knowledge of mass of the charge in point $1\left(\mathrm{p}_{1}, \mathrm{~T}_{1}\right.$ are assumed, R - individual gas constant for the air is known) and assumed value of the excess air ratio $\lambda$ :

$$
\mathrm{m}_{\mathrm{f}}=\frac{\mathrm{m}_{1}}{\lambda\left(\frac{\mathrm{A}}{\mathrm{F}}\right)_{\mathrm{s}}}
$$

where $(\mathrm{A} / \mathrm{F})_{\mathrm{s}}$ is a ratio of air $(\mathrm{A})$ to fuel $(\mathrm{F})$ for an applied liquid or gaseous fuel. The temperature at point 3 is calculated on the base of internal energy balance during isochoric process:

$$
\left.\left(\mathrm{m}_{1}+\mathrm{km}_{\mathrm{f}}\right) \mathrm{c}_{\mathrm{v}}\right|_{0} ^{\mathrm{T}_{3}} \mathrm{~T}_{3}=\left.\mathrm{m}_{1} \mathrm{c}_{\mathrm{v}}\right|_{0} ^{\mathrm{T}_{2}} \mathrm{~T}_{2}+\mathrm{km}_{\mathrm{f}} \mathrm{W}_{\mathrm{d}}
$$

where $\mathrm{k}$ is a part of fuel consumed during combustion process (value is assumed or determined during experimental tests). The temperature $T_{3}$ is obtained from the following equation by several iteration processes determining each time the heat at constant volume $c_{v}$ appropriate for previously calculated temperature $T_{3}$, because $c_{v}=f(T)$ :

$$
\mathrm{T}_{3}=\frac{\left.\mathrm{m}_{1} \mathrm{c}_{\mathrm{v}}\right|_{0} ^{\mathrm{T}_{2}} \mathrm{~T}_{2}+\mathrm{km}_{\mathrm{f}} \mathrm{W}_{\mathrm{d}}}{\left.\left(\mathrm{m}_{1}+\mathrm{km}_{\mathrm{f}}\right) \mathrm{c}_{\mathrm{v}}\right|_{0} ^{\mathrm{T}_{3}}}
$$

Pressure at point 3 is the same as at point 4 and is obtained from the general equation of the gas state: 


$$
\mathrm{p}_{3}=\frac{\left(\mathrm{m}_{1}+\mathrm{km}_{\mathrm{f}}\right) \mathrm{RT}_{3}}{\mathrm{~V}_{2}}=\mathrm{p}_{4}
$$

For isobaric process (3-4) the specific heat at constant pressure $c_{p}$ and individual gas constant $R$ are defined by the following dependencies:

$$
\mathrm{c}_{\mathrm{p}}=\mathrm{c}_{\mathrm{v}}+\mathrm{R} \quad \mathrm{R}=\frac{\mathrm{MR}}{\mathrm{M}}
$$

Temperature in point 4 is calculated from energy balance assuming that whole dose of fuel is burned at point 4 . Similarly to the isochoric process the temperature $T_{4}$ is obtained by several iteration processes determining each time the heat at constant pressure $c_{p}$ appropriate for previously calculated temperature $T_{4}$, because $c_{p}=f(T)$ :

$$
\mathrm{T}_{4}=\frac{\left.\left(\mathrm{m}_{1}+\mathrm{km}_{\mathrm{f}}\right) \mathrm{c}_{\mathrm{p}}\right|_{0} ^{\mathrm{T}_{3}} \mathrm{~T}_{3}+(1-\mathrm{k}) \mathrm{m}_{\mathrm{f}} \mathrm{W}_{\mathrm{d}}}{\left.\left(\mathrm{m}_{1}+\mathrm{m}_{\mathrm{f}}\right) \mathrm{c}_{\mathrm{p}}\right|_{0} ^{\mathrm{T}_{4}}}
$$

One can determine the cylinder volume at point 4 from the gas state equation:

$$
\mathrm{V}_{4}=\frac{\left(\mathrm{m}_{1}+\mathrm{m}_{\mathrm{f}}\right) \mathrm{RT}_{4}}{\mathrm{p}_{4}}
$$

Pressure and temperature of the final point of expansion process (opening of exhaust ports) is determined from the following dependencies:

$$
\mathrm{p}_{5}=\mathrm{p}_{4}\left(\frac{\mathrm{V}_{4}}{\mathrm{~V}_{5}}\right)^{\mathrm{m}} \quad \mathrm{T}_{5}=\mathrm{T}_{4}\left(\frac{\mathrm{V}_{4}}{\mathrm{~V}_{5}}\right)^{\mathrm{m}-1}
$$

In theoretical Atkinson cycle one assumes the equal values of pressure $\mathrm{p}_{6}, \mathrm{p}_{1}$ and $\mathrm{p}_{0}$. Absolute work of each process is defined by change of pressure and volume and for the compression process 1-2 the work has the following form:

$$
\mathrm{L}_{1-2}=\int_{1}^{2} \mathrm{pdV}
$$

Positive work from point 3 to point 6 is determined by the expression:

$$
\mathrm{L}^{+}=\mathrm{p}_{3}\left(\mathrm{~V}_{4}-\mathrm{V}_{3}\right)+\frac{\mathrm{p}_{4} \mathrm{~V}_{4}}{\mathrm{~m}-1}\left[1-\left(\frac{\mathrm{V}_{4}}{\mathrm{~V}_{5}}\right)^{\mathrm{m}-1}\right]+\frac{\mathrm{p}_{5}+\mathrm{p}_{6}}{2}\left(\mathrm{~V}_{6}-\mathrm{V}_{5}\right)
$$

The cylinder pressure course during exhaust port opening in the real two-stroke engines takes place as shown in Fig. 6 (linear drop in pressure). Negative work is obtained from the following expression:

$$
\mathrm{L}^{-}=\mathrm{p}_{0}\left(\mathrm{~V}_{1}-\mathrm{V}_{0}\right)+\frac{\mathrm{p}_{1} \mathrm{~V}_{1}}{\mathrm{~m}-1}\left[1-\left(\frac{\mathrm{V}_{1}}{\mathrm{~V}_{2}}\right)^{\mathrm{m}-1}\right]
$$

So total work of Atkinson two-stroke opposed piston engine is a sum of these works. The presented mathematical model is actual also for each type of two-stroke engine. The difference is only the researcher's decision of fuel dose division defined by coefficient $\mathrm{k}$.

\section{Determination of Atkinson cycle parameters}

Geometric parameters of CI 2sOPE Leyland L60 as a starting point were adopted. The engine data is shown in Table 1. They do not present real values Leyland L60 engine.

Table 1. Engine specification

\begin{tabular}{|l|c|}
\hline Rotational speed, rpm & 1500 \\
\hline Bore, mm & 117.6 \\
\hline Stroke cylinder A, mm & 146 \\
\hline Stroke cylinder B, mm & 146 \\
\hline Connecting rod length of cylinder A, mm & 260 \\
\hline Connecting rod length of cylinder B, mm & 260 \\
\hline Compression ratio & 20 \\
\hline Transfer ports opening, deg & 100 \\
\hline Exhaust ports opening, deg & 140 \\
\hline
\end{tabular}

The purpose of the calculations was to determine the trend of changes in operating parameters depending on the change of the timing phases of the exhaust ports in relation to the transfer ports. The real two-stroke heavy duty engine has a chamber of certain volume surrounding the cylinder around the transfer ports named here as "transfer chamber". The similar space exists for the exhaust ports named here as "outflow chamber". The flow model is shown in Fig. 7, where unsteady gas flow inside pipes and through the ports was taken into account (change of pressure waves). The 8 transfer and 8 exhaust ports were assumed for 0D model and CFD model.

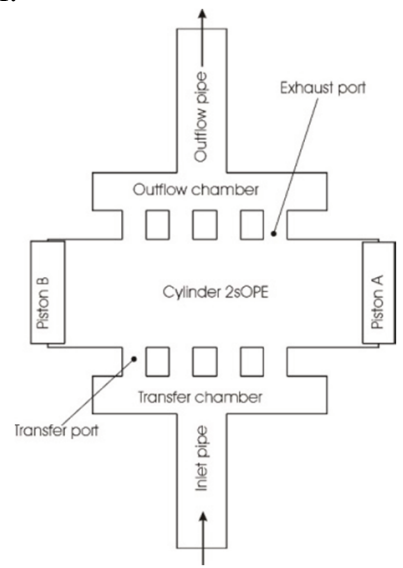

Fig. 7. Calculation model of $2 \mathrm{sOPE}$

Based on the presented mathematical model, geometric data of the engine and assumption of adiabatic processes for perfect gas, thermodynamic parameters of the Atkinson cycle were determined. Calculations were done in the computer program worked out by the author, which enables achieving many other engine parameters. Pressure, temperature and volumes for the points shown in Fig. 6 are presented in Table 2. The minus delay of exhaust port close denotes earlier opening and closing of the exhaust ports in comparison to the symmetric phases. The presented results were obtained at assumption of initial pressure at point 0 and 1 equal 1.013 bar and temperature $293 \mathrm{~K}$ (without charging). 
Table 2. Thermodynamic parameters of theoretical Atkinson cycle of two-stroke engine with opposed pistons

\begin{tabular}{|c|c|c|c|c|c|c|c|c|c|c|c|c|}
\hline delay & $\mathrm{V}_{1}$ & $\mathrm{~V}_{2}$ & $\mathrm{~V}_{4}$ & $\mathrm{~V}_{5}$ & $\mathrm{p}_{2}$ & $\mathrm{p}_{3}$ & $\mathrm{p}_{5}$ & $\mathrm{~T}_{1}$ & $\mathrm{~T}_{2}$ & $\mathrm{~T}_{3}$ & $\mathrm{~T}_{4}$ & $\mathrm{~T}_{5}$ \\
\hline $\mathrm{deg}$ & $\mathrm{l}$ & $\mathrm{l}$ & $\mathrm{l}$ & $\mathrm{l}$ & $\mathrm{bar}$ & $\mathrm{bar}$ & $\mathrm{bar}$ & $\mathrm{K}$ & $\mathrm{K}$ & $\mathrm{K}$ & $\mathrm{K}$ & $\mathrm{K}$ \\
\hline-15 & 2.652 & 0.167 & 0.284 & 2.302 & 48.6 & 126.5 & 6.7 & 293.0 & 885.6 & 2255.6 & 3659.4 & 1583.9 \\
\hline-10 & 2.602 & 0.167 & 0.284 & 2.368 & 47.4 & 123.6 & 6.4 & 293.0 & 879.0 & 2246.3 & 3651.1 & 1563.7 \\
\hline-5 & 2.549 & 0.167 & 0.285 & 2.431 & 46.0 & 120.5 & 5.9 & 293.0 & 871.7 & 2236.3 & 3642.1 & 1544.7 \\
\hline 0 & 2.492 & 0.167 & 0.285 & 2.492 & 44.6 & 117.2 & 5.6 & 293.0 & 863.9 & 2225.4 & 3632.5 & 1526.9 \\
\hline 5 & 2.431 & 0.167 & 0.286 & 2.549 & 43.1 & 113.8 & 5.3 & 293.0 & 855.4 & 2213.8 & 3622.1 & 1510.3 \\
\hline 10 & 2.368 & 0.167 & 0.287 & 2.602 & 41.5 & 110.2 & 5.0 & 293.0 & 846.4 & 2201.4 & 3611.0 & 1494.8 \\
\hline 15 & 2.302 & 0.167 & 0.288 & 2.652 & 39.9 & 106.5 & 4.7 & 293.0 & 836.9 & 2188.3 & 3599.4 & 1480.4 \\
\hline
\end{tabular}

It was assumed, that only 0.3 of dose fuel was burned at isochoric process $(\mathrm{k}=0.3)$. Also, the whole charge was stoichiometric $(\lambda=1)$, which in diesel engine has higher value above 1.2. Earlier closing of the exhaust ports influences on higher pressure and temperature in point 2 and also a little bit on these parameters in point 4 . In the Otto cycle total work is defined by difference between expansion work and compression work. Modelling of the Atkinson cycle enables calculation of the absolute work of the individual thermodynamic processes in dependence on variation of the delay of closing of exhaust ports. These dependencies are presented in Fig. 8. Higher compression work (negative) $\mathrm{L}_{1-2}$ is done for earlier closing of exhaust ports $(-15 \mathrm{deg})$ in comparison to later opening of these ports, but expansion work (positive) is higher for earlier closing of exhaust ports. The work $\mathrm{L}_{3-4}$ is also higher for this case than for later value of $\mathrm{EC}$.

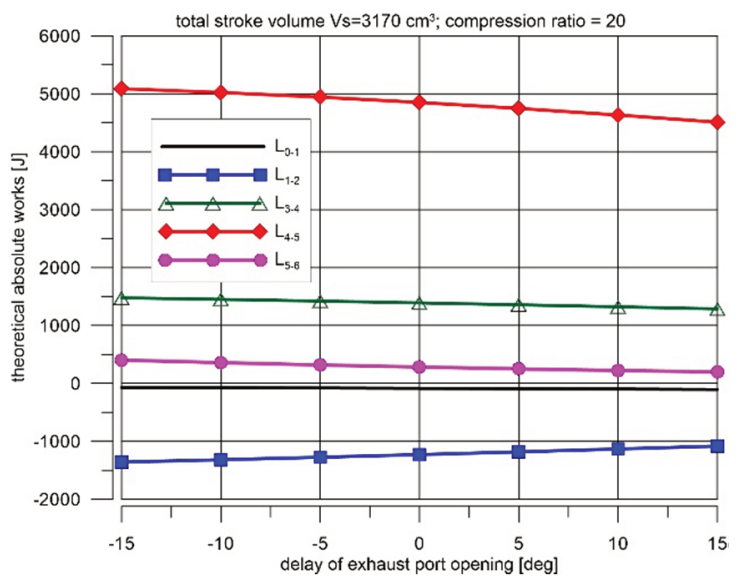

Fig. 8. Theoretical absolute works done during individual thermodynamic processes in a function of delay of opening of exhaust ports

The total theoretical work done by CI according to Atkinson's cycle is a sum of individual works and variation of this work is shown in Fig. 9. There is a significant difference of the total work for delays at $15 \mathrm{deg}-15 \mathrm{deg}$ (about $12 \%$ ). Calculations indicate that for two-stroke engines differently than in four-stroke engines decreasing of the compression process reduces the engine work for the same mass of injected fuel ( $\lambda=$ const). There is almost linear decrease in value of total work with later closing of the exhaust ports.

This phenomenon shows that in the Atkinson cycle shorter compression CA and longer time of expansion process applied in modern 4-stroke engine cannot be used in
2sOPEs. Rather it should be applied the timing with earlier closing of the exhaust ports.

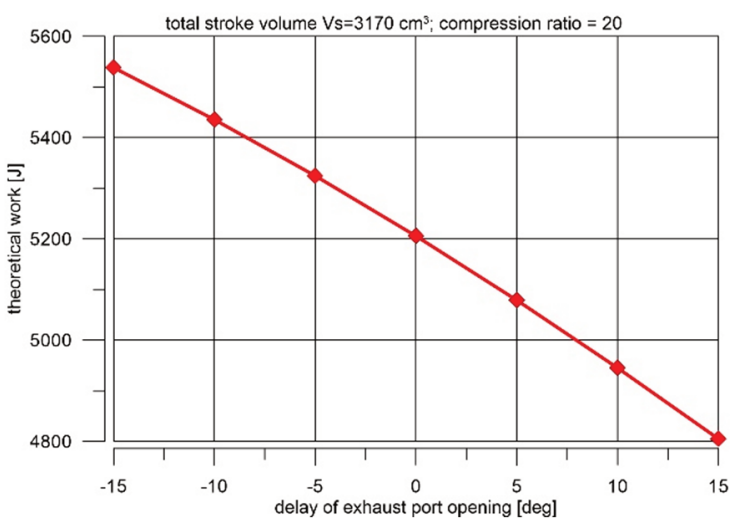

Fig. 9. Theoretical total work done by 2 sOPE in a function of delay of opening of exhaust ports

\section{CFD modelling of engine work}

For the accurate checking of engine thermodynamic parameters, the better is simulation of the work process with CFD program. For that reason, the mesh of such engine was created in pre-processor in KIVA3V [1] with 65840 full hexagonal cells (Fig. 10). The cylinder model contains 8 transfer ports and 8 exhausts port with a certain angle to the cylinder surface, which causes a big swirl of the air in the cylinder during scavenge process. Original KIVA3V program enables calculations of thermodynamic state of the charge during scavenge, combustion and expansion process of two-stroke opposed piston engine.

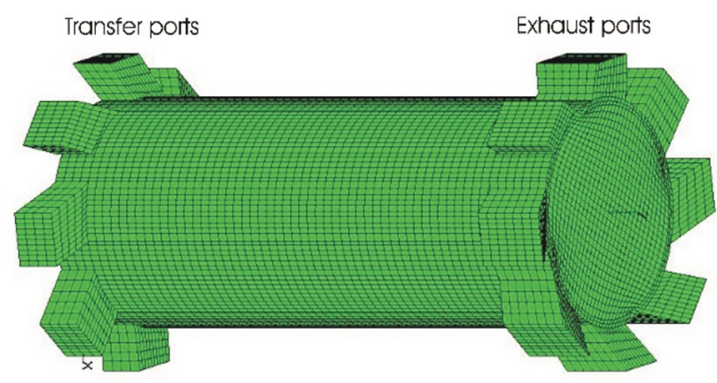

Fig. 10. Mesh of model of Leyland L60 engine

The engine model with the same geometry as shown in Table 1 was analysed at 7 different delay angles of closing of exhaust ports $(-15,-10,-5,0,0.5,10$ and $15 \mathrm{deg})$ at constant engine rotational speed $1500 \mathrm{rpm}$. Turbulence 
model $\kappa-\varepsilon$ was applied. Total mass $0.18 \mathrm{~g}$ of fuel was delivered by 4 injectors located at a half of cylinder height for one working cycle. Diesel oil was injected 8 deg CA BTDC when temperature of the charge was sufficient for selfignition. Fuel injection in two-stroke engines is fully described by author in the book [8]. High swirl ratio caused the peripheral motion of the fuel and quick combustion process. Calculation were conducted at assumption of mechanical charging with absolute pressure equal 1.8 bar at the surface inlet of each transfer port. A fresh air with has temperature of $320 \mathrm{~K}$. Heat transfer to the cylinder and piston walls was considered by using Woschni formulas given by Heywood [6].

The CFD engine working model, in contrast to the theoretical model, takes into account fuel injection, evaporation of fuel droplets and combustion process based on chemical reactions basing on Arrhenius formulas. The results of calculations done for different cases of angle delay of closing of the exhaust ports are presented in the charts shown below. High increase of pressure causes a loud work and big forces acting on the whole crank system. Figure 11 presents cylinder pressure courses at three cases $(-15,0$ and $15 \mathrm{deg}$ ) of CE angles. For earlier closing of the exhaust port the faster increase of pressure during compression process takes place because almost whole delivered fresh air stays in the cylinder. In this case the mixture ignition occurs later and for that reason maximum pressure is lower than for the rest cases. The combustion process is extended on the expansion process. The highest pressure was achieved at symmetrical phases as in classical two-stroke engines. In this case the fuel burns completely in a very short time.

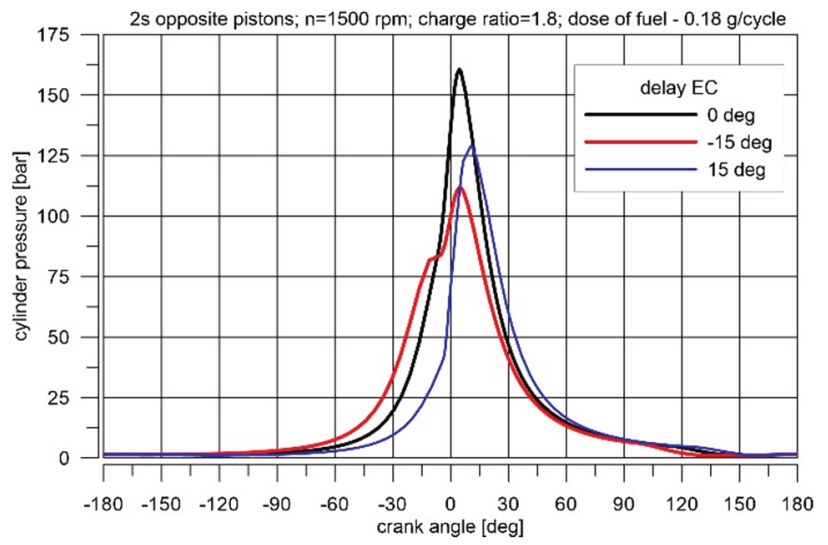

Fig. 11. Cylinder pressure variation in 2sOPE for different delays of exhaust ports closing (EC) in function of crank angle

Variation of mean temperature in the cylinder for three cases is shown in Fig. 12. Starting point of combustion process for delays -15 and 0 deg of exhaust ports closing amounts $1050 \mathrm{~K}$ and is higher than for the case of $15 \mathrm{deg}$ of the delay. Highest temperature takes place at this case 15 deg EC delay and also the highest increment of temperature during combustion process is observed despite the same fuel dose for all cases $0.18 \mathrm{~g} /$ cycle.

Pressure traces in dependence on volume change $(\mathrm{p}-\mathrm{V})$ are shown in Fig. 13 for analysis of engine work. The case with highest pressure does not give highest work. The decision about changing the closing phase of the exhaust ports influences on the engine power. The symmetrical timing phases cause high value of maximal pressure, but it is lower during expansion process. The engine is evaluated in terms of indicated mean effective pressure (imep). Despite of low value of maximal cylinder pressure for the case with delay of -15 deg EC the engine shows higher imep than for the cases with later closing of exhaust ports by the piston (Fig. 14). The difference of imep amounts 1 bar, which is above $10 \%$ of maximal value at $-10 \mathrm{deg}$ EC of delay.

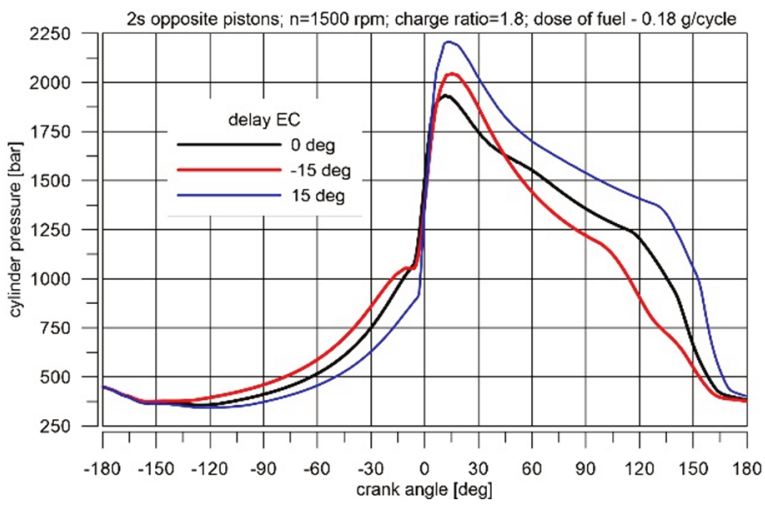

Fig. 12. Temperature course in cylinder for different delays of exhaust port closing

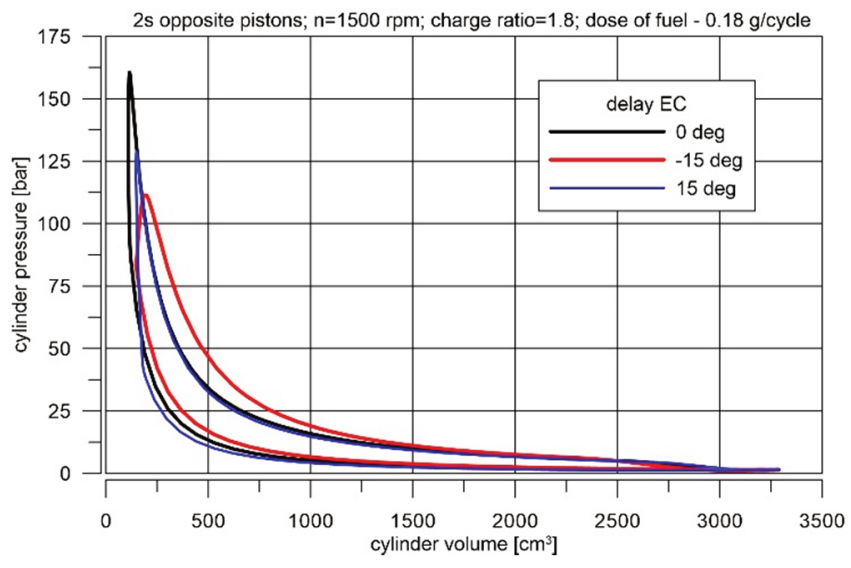

Fig. 13. P-V diagram for different delay of exhaust ports closing (EC)

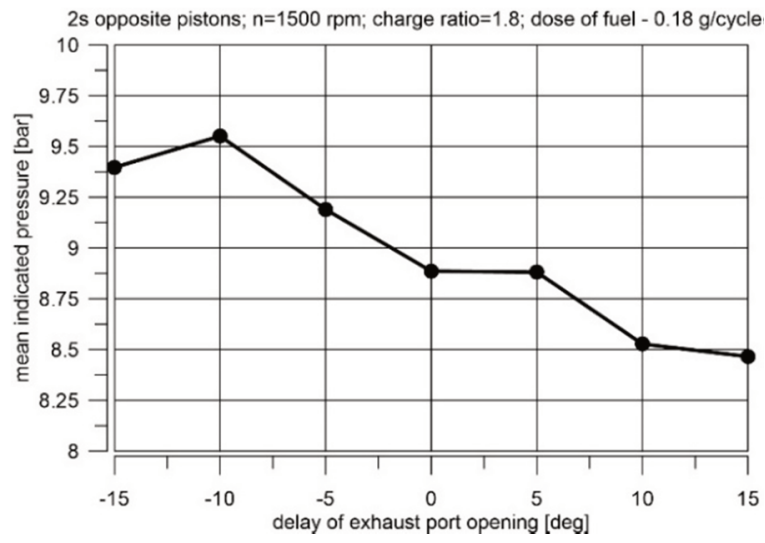

Fig. 14. Variation of mean indicated pressure in dependence of delay of exhaust port close

Total efficiency of the engine is determined by specific fuel consumption (bsfc) and fuel caloric value. Variation of total efficiency of analysed engines is similar as variation of 
imep (Fig. 15). For the low dose of fuel, the engine achieves highest efficiency at $-10 \mathrm{deg}$ CE of delay of $40 \%$. Delay of closing of outflow ports causes a significant decrease of total efficiency.

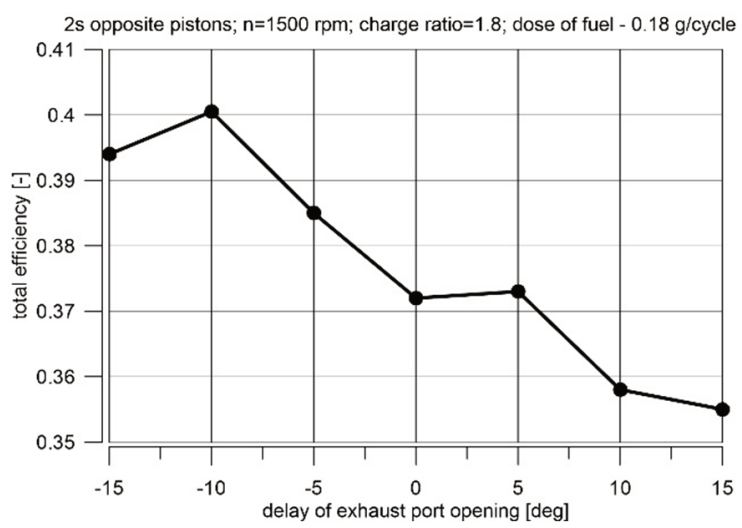

Fig. 15. Variation of engine total efficiency in dependence of delay of exhaust port close

For the same amount of the injected fuel the air excess ratio depends on volumetric efficiency. So, if the excess air ratio increases, it means that the cylinder before combustion process contains a large amount of the fresh air. Figure 15 presents variation of the excess air ratio in dependence of EC delay. For earlier closing of the exhaust ports more air remains in the cylinder. This dependence is almost linear.

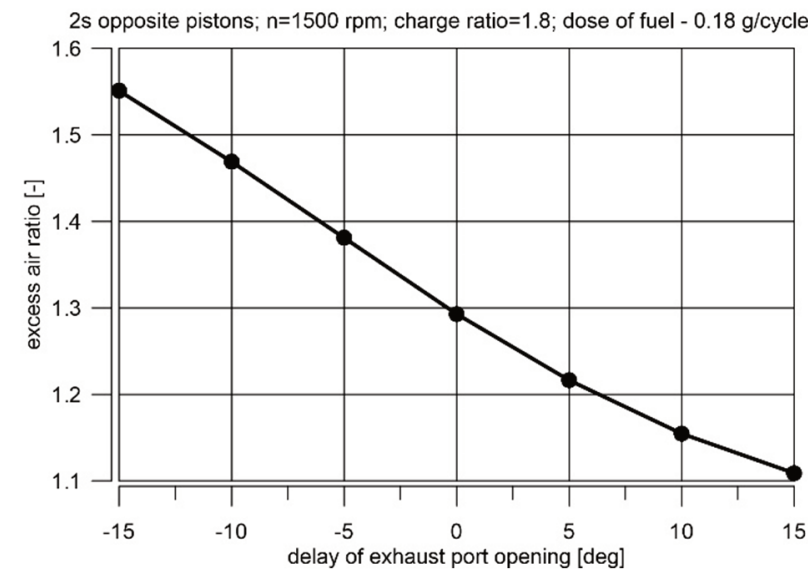

Fig. 16. Air excess ratio $(\lambda)$ as function of delay exhaust port opening

Compression ignition engines emit pollutants, mainly soot in a form of particulate matters (PM) and a lot of nitrogen oxides $\left(\mathrm{NO}_{\mathrm{x}}\right)$. Amount of $\mathrm{NO}_{\mathrm{x}}$ depends on combustion temperature and for the case with $15 \mathrm{deg}$ EC of delay, where maximal mean temperature achieves value $2250 \mathrm{~K}$, the engine emits most of $\mathrm{NO}_{\mathrm{x}}$. The most important product among $\mathrm{NO}_{\mathrm{x}}$ compounds is nitric oxide $(\mathrm{NO})$ and variation of NO mass ratio in the combustion chamber is shown in Fig, 17. Earlier closing of outflow ports causes lower emission of $\mathrm{NO}_{\mathrm{x}}$, but a small amount of hydrocarbons (below 50 ppm) is seen in exhaust gases.

Program CFD enabled achieving more detailed information about scavenge process, spreading of injected fuel, evaporation of fuel droplets, forming of chemical species during combustion process and their distribution inside the cylinder. But these phenomena will be the subject of another dissertation.

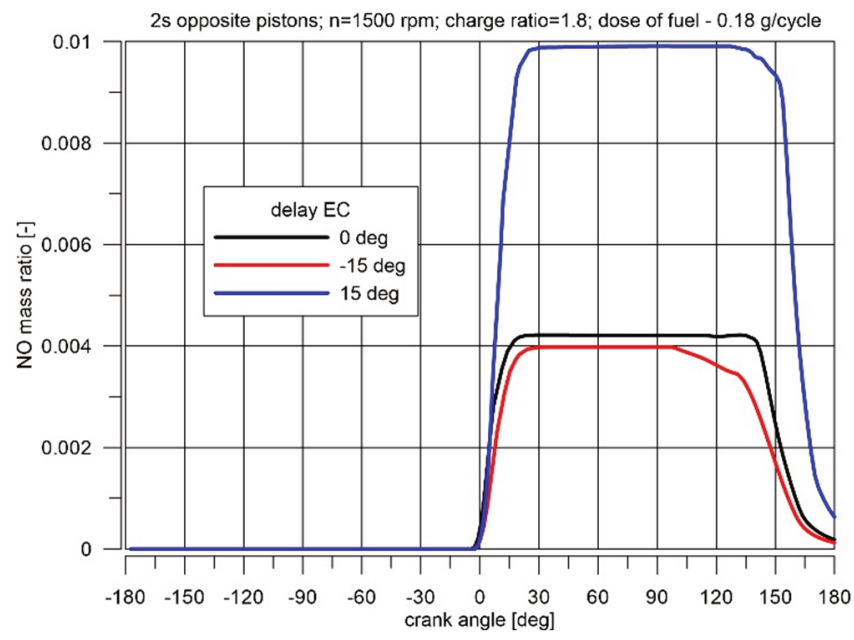

Fig. 17. Variation of NO mass ratio in cylinder of 2 sOPE with different delay of exhaust port closure

\section{Discussion of results}

Recently modification of engine work by the Atkinson cycle is done for many types of engines especially for hybrid vehicles. Typical Atkinson modification by later closing of exhaust and inlet valves in four-stroke engines enables shorter compression period and longer expansion period, which causes less absolute work of compression process and greater expansion work. But in four-stroke engines there is only a small escape of the fresh air during closing of the inlet valves. But it is not true for two-stroke engines especially supercharged engines. Later closing of exhaust port causes an escape of a large amount of the fresh air. For this reason, earlier closing of the exhaust ports just after closing of the transfer ports causes the capture of a larger amount of the fresh air, particularly for charged engine. Then more fuel can be injected in order to achieve more engine power.

Both simulation tests using OD and CFD programs have shown the need for reverse action than in 4-stroke engine. Earlier opening of the exhaust ports and thus its early closure causes more power, higher total efficiency and also lower emission of NOx. The works done in Achates Power, Inc $[4,5]$ also confirm such dependences for their production engines. Earlier opening of exhaust ports in $2 \mathrm{sOPE}$ causes faster escaping of exhaust gases under higher pressure and the scavenge process is more effective particularly in the supercharged engine. The work presents the theoretical Atkinson cycle for $2 \mathrm{sOPE}$ with certain modification of the cycle at outflow with mathematical model. The model is more realistic than it was presented till now.

\section{Conclusions}

The presented study of the engine's work induces to draw some conclusions and guidelines for potential engine designers and researchers. The study is an input for realization of such processes in a future of power plant engines with different fuelling systems.

1. The paper presents a new theoretical cycle of $2 \mathrm{sOPE}$ with Atkinson modification and its mathematical model. 
Such model is useful for analysis of thermodynamic parameters at assumption of different settings of openings the engine ports by change the angular cranks settings.

2. Two-stroke opposed piston diesel engines enables to apply an asymmetric timing of exhaust ports phases, which allows to reduce the loss of the fresh charge during scavenge process.

3. Such engine causes a strong swirl of the charge during scavenge process, which influences on a good penetration of the injected fuel and enable better combustion process.

4. Applying of Diesel/Atkinson cycle in the two-stroke OPE by earlier closing of the exhaust ports increases working parameters (imep, total efficiency and volumetric efficiency). Much more fresh air stays in the cylinder after and therefore much more fuel can be delivered by the injector, which enable to achieve more power.

5. Despite shorter expansion time the expansion work of this engine is bigger at earlier exhaust port opening than at later opening.

6. The combustion process in the diesel-Atkinson $2 \mathrm{sOPE}$ lasts longer at constant pressure but at lower value of pressure, which is important for durability of whole crank system.

7. 2sOPE with earlier opening of exhaust ports enable decreasing of $\mathrm{NO}_{\mathrm{x}}$ due to lower combustion temperature.

8. Inversely than in the four-stroke engine, for more work, the outlet ports must be opened earlier.

\section{Nomenclature}

2sOPE two-stroke opposed piston engine

CE closing of exhaust port

TDC top dead centre

BDC bottom dead centre

imep indicated mean effective pressure bsfc brutto specific fuel consumption

PM particulate matters

CFD computational fluid dynamics

CI compression ignition engine

\section{Bibliography}

[1] AMSDEN, A.A. et al. KIVA: a comprehensive model for 2D and 3-D engine simulations. SAE Paper 850554. 1985.

[2] EBRAHIMI, R. Thermodynamic modeling of an Atkinson cycle with respect to relative air-fuel ratio, fuel mass flow rate and residual gases. Acta Physica Polonica A. 2013, 124. DOI:10.12693/APhysPolA.124.29

[3] FLINT, M., PIRAULT, J.P. Opposed piston engines: evolution, use, and future applications. SAE International. Warrendale. 2009.

[4] FOSTER, D., HEROLD, R., LEMKE, J. et al. Thermodynamic benefits of opposed-piston two-stroke engines. $S A E$ Technical Paper 2011-01-2216. 2011, DOI:10.4271/201101-2216

[5] FROMM, L., HEROLD, R., KOSZEWNIK, J., REGNER, G. Modernizing the opposed-piston engine for more efficient military ground vehicle application. 2012 NDIA

Wladyslaw Mitianiec, DSc., DEng. - Faculty of Mechanical Engineering, Cracow University of Technology.

e-mail: wmitanie@usk.pk.edu.pl
Ground Vehicle Systems Engineering and Technology Symposium. Michigan, August 14-16, 2012.

[6] HEYWOOD, J. Internal Combustion Engine Fundamentals. McGraw-Hill. New York, 1988.

[7] http://en.wikipedia.org/wiki/Atkinson_cycle

[8] MITIANIEC, W. Fundamentals of fuel injection and emission in two-stroke engines. Nova Science Publisher. New York 2018.

[9] NOBUKI, K., KIYOSHI, N., TOSHIHIRO, K. Development of new 1.8-1 engine for hybrid vehicles. SAE Technical Paper 2009-01-1061. 2009.

[10] REGNER, G. et al. Modernizing the opposed piston twostroke diesel engine for more efficient commercial vehicle applications. Achates Power, Inc. San Diego 2012.

[11] SENDYKA, B., SOCHAN, A. Increase of the total efficiency using the Atkinson cycle in the spark ignition engine. Journal of KONES Powertrain and Transport. 2009, 16(2). 